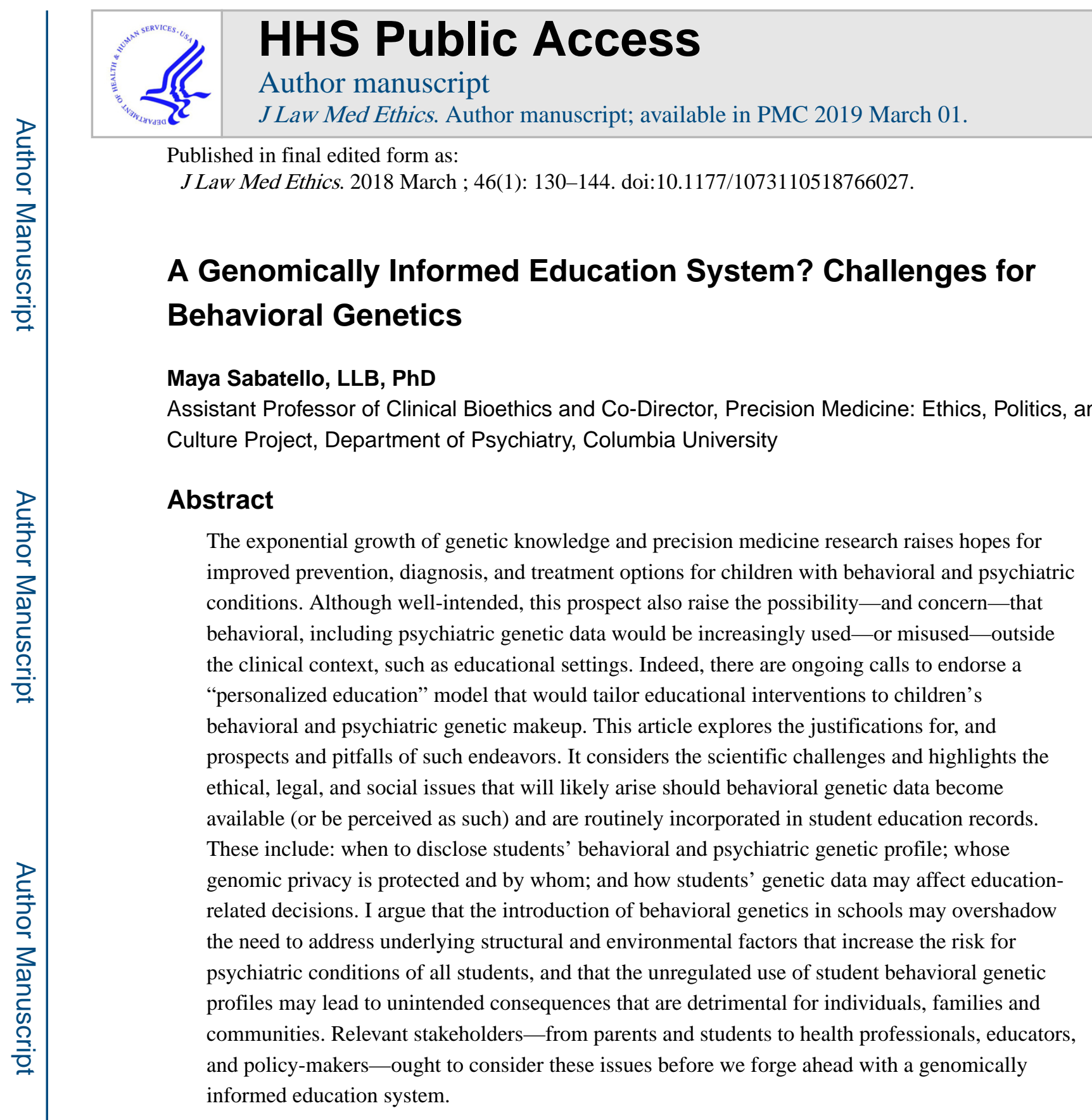

\title{
Introduction
}

Knowledge of genetics is expanding at an exponential rate. Since the completion of the Human Genome Project in 2003, numerous genes that contribute to the development of disorders have been identified. Although isolating genes relevant to behavioral and psychiatric disorders has been more challenging, efforts are ongoing to identify and better understand the genetics of such complex conditions. These endeavors are further likely to accelerate with the rise of large biospecimen cohorts, including the All of Us Research Program (previously called, the Precision Medicine Initiative), and raise hopes for improved prevention, diagnosis, and treatment options for adult and pediatric patients with psychiatric

Address correspondence to Dr. Sabatello at: NY State Psychiatric Institute, 1051 Riverside Drive, Unit 122, New York, NY 10032. Phone: work - 646-774-8630, fax - 212-543-6752. ms4075@columbia.edu. 
conditions. Significantly, behavioral genetic data-a term used in this article to connote inherited behavioral, including psychiatric and neurodevelopmental, conditions such as aggression, depression, and attention deficit hyperactivity disorder (ADHD) — are also increasingly being used, or considered for use, in non-clinical contexts.

One such example is school settings. Although in its infancy stages, there are increasing calls to utilize genomic knowledge to develop "personalized education," whereby interventions in classrooms will be tailored to a child's behavioral and other neuropsychiatric genetic makeup. ${ }^{1}$ As proponents of a genomically informed education system postulate, understanding the genetic bases of behaviors that impact learning-related processes will enable identification of environmental and pharmacological interventions that may enhance students' educational achievements. ${ }^{2}$ Although some may view such a genomically sensitive education system as appealing, the prospect of behavioral genetic data becoming available and incorporated in students' education records faces significant scientific challenges and also raise a host of ethical, legal, and social issues, including the possibility — and concern — that such data would be misused in school settings.

This concern of misuse of student medical information is not unique to behavioral genetic data. In the early $20^{\text {th }}$, as cities in the U.S. began paying attention to sanitary conditions in schools and begun requiring that certain health services are provided, they also instituted mandatory daily medical inspection of students — carried out by nurses and physicians - to identify and exclude those with contagious conditions from schools. ${ }^{3}$ Although this medical inspection enabled reducing the spread of major communicable conditions such as measles, in practice, even minor and preventable diseases such as head lice served as a reason to send children home. Without a simultaneous duty that such children receive care, this practice was particularly detrimental for poor children whose educational and employment prospects were negatively impacted as a result of this exclusion. ${ }^{4}$ More recently, stigma surrounding HIV/AIDS has led to school children being denied admission and educational opportunities because of their real-and suspected-HIV-positive status. ${ }^{5}$ However, the innate nature of behavioral genetic data, coupled with stigma and genomic illiteracy among educators, the general public and healthcare professionals, raise an even greater risk of misunderstanding and misuse of student medical information.

This article explores the justifications for, and prospects and pitfalls of disclosure of student behavioral genetic profiles in school settings. Although there is currently no genetic test that can provide a diagnosis of a behavioral and psychiatric disorder or an accurate estimate of a person's proclivity for such conditions (some rare exceptions of genetic syndromes exist, e.g., Fragile X), ${ }^{6}$ studies that focus on candidate genes and, especially, genes that interact with environmental factors to produce psychopathological outcomes are ongoing and there is high hope that the use of next-generation sequencing technologies and large cohorts (e.g., the Psychiatric Genomic Consortium's dbGaP datasets) will yield more systematic findings. 7 The history of the scientific technologies further suggests that scientists' and lay public's endorsement of genomic-based practices, including more controversial ones, often occurs over time, and moreover, that genomic data are increasingly being used in non-clinical settings and daily lives, sometimes, also when the scientific validity of findings is weak. Thus, it is plausible to assume that the introduction and use of student behavioral and 
psychiatric genetic data in school settings will become more common once genetic testing with sufficiently high positive predictive power for such conditions is developed.

Conversely, and more concerning, is the possibility that without policies to regulate genomic uses in non-clinical settings, stakeholders will try to introduce behavioral genetic findings in schools, regardless of the evidence-base of the data.

Accordingly, the next section considers the rise of uses of genomic data in clinical and nonclinical contexts, followed by a discussion about the increasing use of and support for genetic screening programs in educational institutions, to project about the probability of behavioral genetic data entering into school settings. I then discuss the challenges for a genomically informed education system. First, I provide the scientific landscape of, and obstacles in current (and likely future) study of behavioral and psychiatric genetics, and the relevance thereof for a genomically sensitive education system. Second, I consider the ethical, legal, and social issues that will likely to arise should behavioral genetic data become available (or be perceived as such) and are routinely incorporated in student education records, specifically: when to disclose students' behavioral and psychiatric genetic profile; whose genomic privacy is protected and by whom; and how students' genetic data may affect education-related decisions. I argue that the introduction of behavioral genetics in schools may overshadow the need to address the underlying environmental and structural factors that increase the risk for psychiatric conditions of all students, and that the unregulated use of student behavioral genetic profiles may lead to unintended consequences that are detrimental for individuals, families and communities. Relevant stakeholders-from parents and students, to health professionals, educators, and policy-makers-ought to consider these issues before we forge ahead with a genomically informed education system.

\section{The "Genomicization" of Medicine and Everyday Life}

As the pace of genomic knowledge advances in giant steps and sophisticated technologies allow generating genomic data at plummeting costs, genomic applications are becoming more and more relevant for medical practice and everyday life. Since the completion of the Human Genome Project in 2003, and the subsequent development of next-generation sequencing such as Whole Genome and Exome Sequencing, the number of genetic tests that are performed in clinical and research settings has sparked. It is estimated that $\sim 4$ million infants in the U.S. undergo newborn screening each year, and while current programs focus on metabolic, hematologic, and endocrine conditions for which early prevention or intervention are available, ${ }^{8}$ there are ongoing initiatives to expand newborn screening programs to next-generation sequencing. ${ }^{9}$ The number of children who are tested for various neuropsychiatric syndromic conditions, including those associated with intellectual disabilities is on the rise, ${ }^{10}$ as is the number of children who participate in studies that utilize next generation sequencing technologies ${ }^{11}$ and are offered at least some return of results. ${ }^{12}$

The ongoing expansion of genomic-based practices-including some of the most controversial ones-is further useful in projecting whether and how children's behavioral genetics may be obtained and used in the future. For instance, the use of pre-implantation genetic diagnosis technique began with significant public turmoil but has become more common, ${ }^{13}$ and its original aim of identifying monogenic and sex-linked disorders has 
expanded to include over 100 conditions, including testing for genetic disorders with low penetrance and late-onset conditions. ${ }^{14} \mathrm{~A}$ long and extensive debate about the permissibility of mitochondrial replacement therapy has culminated in 2015 into its approval for use in the U.K., ${ }^{15}$ and 2016 recommendation to approve testing for this procedure in the U.S. ${ }^{16}$ Germline gene editing - another practice that, for years, was viewed as "off limits" for researchers and NIH-approved protocols-was recommended in late 2016 for clinical trials by the National Academy of Sciences and National Academy of Medicine. ${ }^{17}$ And, the 2013 setback on the market of direct-to-consumers (DTC) genetic testing companies that offered (dubious) genetic-based health risk assessment for psychiatric disorders ${ }^{18}$ is already reversing its course. In 2015, the Food and Drug Administration allowed 23andMe to offer tests for carrier status of over 40 inherited conditions,${ }^{19} 10$ additional genetic tests, including for Alzheimer Disease were approved in April 2017. ${ }^{20}$ Given findings that many parents are interested in utilizing the services of DTC genetic testing companies to test their children for common diseases, ${ }^{21}$ and that parents express high interest in genetic testing of their young children for psychiatric predispositions, ${ }^{22}$ it seems likely that aside from clinical testing of symptomatic children, a market for pediatric genetic testing for behavioral and psychiatric conditions (once available and permitted for DTC marketing) may develop as well.

The uses of behavioral genomic data have additionally begun to expand beyond their intuitive clinical and research locales to encompass non-clinical and non-research settings. Although behavioral genetic research with actionable findings is still in its infancy, stakeholders seem eager to utilize emerging findings—also when the replicability and scientific accuracy of these findings are questioned ${ }^{23}$ - to advance their cause. Indeed, behavioral genetic claims have already made their way into criminal procedures, ${ }^{24}$ child custody proceedings, ${ }^{25}$ and tort litigation; ${ }^{26}$ other civil arenas such as real property rights are currently being considered ${ }^{27}$ as is the incorporation of knowledge about epigenetic processes such as DNA methylation that may impact the development of psychiatric disorders ${ }^{28}$ into life insurance's policy and assessment of consumers' mortality predictions. ${ }^{29}$

Significantly, there are signs that the genomicization of daily life is making its way also into educational settings. As Francis Collins had envisioned, as we move to maximize a genomics-based health care, it will become more and more compelling to learn about genetic risk factors and to consider effective interventions for them at birth, ${ }^{30}$ and an array of new users of such data, including educational institutions, are likely to emerge. ${ }^{31}$ As discussed in the next section, not only that this trend is likely to increase, but the rationales for using student genetic data in schools may be of particular relevance for behavioral genetics.

\section{The Road to Student Behavioral Genetics in School Settings}

The notion that schools and student genetics can intersect is not new. In 1972, Montreal launched the first pilot program to screen (primarily Ashkenazi Jewish) adolescents in high school for carrier status of Tay Sachs Disease, a neurodegenerative condition that usually results in death by age $5 .{ }^{32}$ While the goal of this and most of the subsequent screening programs in high schools has been to increase informed reproductive choices, the scope of testing and the justifications thereof have undergone notable changes over time. Thus, e.g., 
screening programs in high schools that developed since the mid-1990s in Australia, Israel, Hong Kong, and the US have expanded to include testing for carrier status of genetic conditions that are less severe than Tay Sachs, such as Cystic Fibrosis. ${ }^{33}$ In addition, high school-based screening programs for personal health reasons-i.e., to identify increased risk to a condition or increased risk for susceptibility to a condition ${ }^{34}$ - are slowly emerging as well. In 2007, e.g., a pilot program in Australia began offering high school students genetic susceptibility testing for hereditary haemochromatosis, an adult onset treatable and preventable disorder that causes the body to absorb too much iron from the diet. ${ }^{35} \mathrm{~A}$ total of 5,757 high school students were subsequently tested for this condition (consent was obtained from both parents and students), leading the researchers to conclude that genetic susceptibility screening in high schools was both feasible and acceptable to stakeholders in school communities. ${ }^{36}$

College and university settings are also becoming hot spots for student genetic testing. To date, several leading medical institutions (e.g., Stanford and Icahn/Mount Sinai) have already developed and implemented courses that include students' analysis of their own genome. ${ }^{37}$ Although these courses enrolled only health professionals (including medical students and MA genetic counseling students) and aimed to provide experiential training as a way to improve patients' care, in the future such initiatives may expend to other types of students. Another example is the 2010 decision of the National Collegiate Athletic Association (NCAA) to require student-athletes to be screened for a genetic sickle cell trait prior to participating in college sports (student-athletes can opt out of testing after attending an educational session). ${ }^{38}$ Although sickle cell is not a behavioral/psychiatric condition, the rationale for the NCAA's position is important: the expectation that screening will enable school athlete trainers to tailor the practice protocol to students who test positive. ${ }^{39}$

Other large-scale collegiate genetic programs focus specifically on behavioral genetics. In 2010, e.g., Berkeley University mailed saliva sample kits to all incoming students and offered them individualized DNA analysis as a way to promote healthier life choices among students. ${ }^{40}$ While the program required students' consent, it planned to conduct the DNA analysis in-house, at a University's lab, and to focus on specific gene variants-most pertinent here: genes that regulate the ability to metabolize alcohol—with test results being preserved as data sets on the University's computers. And, in 2011, Virginia Commonwealth University launched its university-wide "Spit for Science" study. ${ }^{41}$ This longitudinal studywhich has since enrolled nearly $70 \%$ of its incoming freshman class each year to participate in the project, with $97 \%$ also choosing to participate in the genetic component-aims to improve understanding of the impact of genes, environments and developmental factors on complex behavioral health outcomes (alcohol use, related substance use and mental health) and to develop tailored prevention and intervention strategies based on the findings. ${ }^{42}$

Taken together, it seems plausible to assume that student behavioral genetic data will become increasingly appealing for use in elementary and high school settings. First, the rationales for students' genetic testing — specifically, the interests in identifying risks for and taking preventative measure to reduce the prevalence of certain health conditions-may be particularly strong for behavioral genetics. Aside from the impact of behavioral and psychiatric conditions on personal development, studies show that children with such 
conditions are more likely to drop out of school, ${ }^{43}$ to be unemployed as adults, ${ }^{44}$ and to enter the criminal justice system. ${ }^{45}$ There are thus both individual and societal interests in reducing the prevalence of psychiatric conditions among children. Second, emerging studies about gene and environment interactions and epigenetics processes that impact the development of psychiatric disorder (see e.g. ${ }^{46}$ ) could inform efforts to tailor personal and professional responses to students' genetic makeup (see further discussion below). As proponents of a genomically informed education system suggest, student behavioral genetic data can promote early identification of children at risk of developing behavioral and psychiatric conditions, advance new preventive educational and developmental tools, and enable more effective individualized pharmacological interventions and provision of tailored services to help such children in school settings. ${ }^{47}$ Indeed, some scholars further emphasize that the notion of a personalized education, which has originated in the context of special education, should be more readily available and universally endorsed in mainstream classrooms to support higher educational attainment for all students. ${ }^{48}$

Finally, the views of relevant stakeholders-researchers, parents, students, and educational staff and professionals - about genomic knowledge, especially behavioral genetics, further demonstrate the likely interest in a genomically sensitive education. A growing body of research aims to shed light on the impact of behavioral genetics and environmental factors on educational achievement, ${ }^{49}$ and to provide recommendations for specific interventions in the classroom (presently primarily) for behavioral phenotypes that are associated with genetic syndromes. For instance, educators are advised to sit side-on rather than face-on when working with children with fragile $\mathrm{X}$ syndrome due to heighted anxiety and gaze aversion among such children. ${ }^{50}$ Beyond special education settings, there are calls for genomic-based educational studies that will include multiple family members (beyond twins) to better understand child outcomes that are influenced by family/classroom or family/school interactions. 51

Studies of parents and potential parents indicate high interest in genetic testing of their children for behavioral and psychiatric predispositions, preferably before adolescence, ${ }^{52}$ strong perceptions about the impact of both genetics and the environment on children's behavioral and psychiatric conditions, ${ }^{53}$ and support for preventative behavioral, environmental and therapeutic interventions on the basis of children's genetic susceptibility for such disorders. ${ }^{54}$ These parental views are particularly important for elementary school children whose parents are entrusted to make medical decisions on their behalf, including undergoing genetic testing. However, they are also relevant for adolescents who are legal minors but who are also increasingly involved, and opinionated about, whether to undergo genetic screening. As the Australian study mentioned above found, not only that parents of high school students indicated that they supported the idea of a school-based screening program for genetic susceptibility testing, but students expressed even more positive views about such screening than their parents, with $35 \%$ of students $(n=748)$ further suggesting that they alone should give consent. ${ }^{55}$ Although the Australian studies did not focus on behavioral genetics, their findings are useful in thinking about the role of students and parents as stakeholders in such genomic-based initiatives and the trajectory of using behavioral genetic data in schools. 
Relevant studies with educators are few but significant. A 2005 survey of 667 primary school teachers in the UK found that many believe in the influence of both genetics and environmental factors on student behavioral traits. ${ }^{56}$ However, while $57 \%$ of teachers believed that behavioral conditions such as hyperactivity are more influenced by environments than genetics, $91 \%$ of them believed that genetics accounts for at least half of the influence for psychiatric conditions. Importantly, $82 \%$ of teachers responded that knowing that a student had a genetically-influenced learning difficulty will influence their methods of instructing and tracking students, and overall, teachers expressed hope that "future genetically-sensitive research would provide solutions for the field of education" (p. $15)$, such as early identification of learning-related issues, and facilitation of effective preventative action. Similarly, a 2004 Australian study found that teachers held positive attitude towards genetic susceptibility testing in schools and reported that they would like their students to be offered such testing, the primary reasons being early detection and better management of the condition. ${ }^{57}$ Finally, a study in Denmark that offered high school students ancestral testing through a DTC genetic testing company resulted in over 700 students who were genotyped and to which the researchers had access to their genetic data (the researchers limited the number of participants due to budgetary reasons). ${ }^{58}$ Although this study did not involve medically relevant information or behavioral genetics, its' importance lies in the response of educators who were the ones to be initially recruited to the study and assigned to introduce it to their schools. As the researchers described, teachers' response was "overwhelming" and "warm," with as many as 40 out of 168 high schools in the country expressing interest in joining the project.

Concurrently, efforts are underway to enhance educational psychologists' embrace of research on the nature and nurture of behavioral traits and involvement in developing a genomically sensitive education system. These includes calls to expand current team-based approaches in education to encompass not only pediatricians, educators, and mental health providers, but also professionals with expertise in behavioral medicine, genetic counseling, and genomics (so-called "educogeneticists") who will make "informed recommendations to both schools and families," 59 and to require that educational psychologists actively consider how to translate genetically sensitive research into educationally relevant goals such as reducing classroom behavioral problems and improving academic performance. ${ }^{60}$ With laws and court cases expecting educators and schools to conduct "full and individual" evaluation for children with behavioral issues before they develop individualized educational plans, ${ }^{61}$ it is thus plausible that should behavioral and psychiatric genetic testing achieve sufficiently high positive predictive power-or be perceived by stakeholders as having such power-it could be viewed as a first step in "footing the bill."

Nonetheless, the calls for a genomically sensitive education system require scrutiny. In particular, the prospect of introducing student behavioral genetic data in schools raises scientific challenges as well as the risk of misuse and misinterpretation of student genetic information. 


\section{Is the Science There? Will It Ever Be?}

A prime challenge for the trajectory of an educational system that is tailored to students' behavioral genetic makeup is the limitations of the scientific study itself, that is: the difficulty in finding robust and replicable associations between traits and genes. ${ }^{62}$ Although it is well established that common behavioral and psychiatric disorders run in families and that this is largely due to genetic inheritance, the etiology and genetic architecture of such conditions are complex. ${ }^{63}$ They are highly polygenic, involving multiple genes with each contributing only subtle effect size to the overall risk of developing a disorder. Identifying a gene or even several genes that can be associated with the development of psychiatric conditions is thus unlikely (some rare exceptions of syndromic conditions exist, e.g., 22q11.2 deletion that significantly increases the risk for psychiatric disorders, ${ }^{64}$ including anxiety and attention deficit hyperactivity disorder (ADHD) in children ${ }^{65}$ ). Furthermore, studies demonstrate that environmental factors such as stress during pre and postnatal neurodevelopmental periods, and, especially, gene-environment interactions, including epigenetic processes, are prominent for increasing the risk of developing psychiatric conditions. ${ }^{66}$ However, because neither the genetic nor environmental causes are linear or additive, it is very difficult to specify which environmental factors, and to what extent each one of them, influence behavioral and psychiatric outcomes. ${ }^{67}$ As a result, current behavioral genomic research is far from fathoming the complexity of human behavioral and psychiatric traits, let alone translating behavioral genomic knowledge into behavioral, environmental, and pharmacological interventions that are tailored to individuals' genetic make up.

Whether this scientific state of affairs will change in the future is unresolved. For some, the prospect is "gloomy" 68 with doubts about the likelihood of continued behavioral genomic research to result in genomic-based personalized psychiatry as has been envisioned for other realms of medicine. ${ }^{69}$ Others are more optimistic, holding that the tremendous expansion of knowledge base in psychiatric genetics in the past decade and the pace of transformation in knowledge, which is unprecedented in the history of the field, should serve as hindsight for future progress. ${ }^{70}$ Thus, given the promise of genome-wide association studies (GWAS) to identify large numbers of risk loci, ${ }^{71}$ and the increased availability of large sample sizes for research — a major challenge for psychiatric genomics-there is hope that ongoing research will lead to more robust findings and tailored drug development. ${ }^{72}$

Still, however, how such scientific advances, which are geared towards clinical care, will be translated into non-pharmaceutical, classroom interventions to produce improved educational achievement remains unknown. The complexity is further compounded by the phenotypic heterogeneity that exists within groups: educational interventions that are recommended on the basis of behavioral genetic findings at the group/population level may be off target for individual children, even when these children share a genetic syndrome or proclivity with the larger group. ${ }^{73}$ It is difficult to see how teachers and others in the education system will be able to navigate these issues, especially in poverty stricken neighborhoods where the resources are significantly limited. 
While the calls for using behavioral genetics in school are (at least) presently premature, consideration of the ethical, legal, and social issues that would arise from such uses is merited. Indeed, if the science progresses to provide sufficiently powerful findings, or more concerning, regardless of the scientific validity of findings, stakeholders may try to introduce and use student behavioral data in school. In turn, this prospect raises the risk of misuse and misinterpretation of student genetic information, and families, health professionals, educators, and policy makers should consider several issues before such data become available and are routinely incorporated in student education records. These include: when to disclose students' behavioral genetic profile; whose genomic privacy is protected and by whom; and how students' genetic data may affect education-related decisions.

\section{The When Question}

Given that the identification of students with behavioral and psychiatric disorders is important for advancing individual's and societal interests, the incorporation of genetic data in student education records-most likely through parents' or health professionals' provision of information-may appear as a straightforward measure to attaining these goals.

Moreover, disclosure of a student's behavioral genetic profile may be unavoidable if educators are to implement, and students are to enjoy, the benefits of a genomically informed education system. Indeed, education law and guidelines already permit school officials to access student education records, including health information generated for such records, without parental consent, when certain conditions are met. Importantly, as stipulated in the Family Educational Rights and Privacy Act (FERPA), a Federal law that applies to all public schools and virtually to all private schools as recipients of federal funds, one such condition is that the access to student medical records serves a "legitimate educational interest." 74

However, questions arise as to which circumstances other than those directly aimed at benefiting a student's educational skills would justify disclosure of his/her behavioral and psychiatric genetic profile. In a recent court case, for example, a teacher disclosed to parents of two children with active cystic fibrosis (CF) that another student named CC was found to be a carrier of genetic markers associated with CF (Chadam case, 2014). ${ }^{75}$ The parents subsequently requested, and the school district ultimately accepted, that $\mathrm{CC}$ be removed from the school. As explained in the court proceedings, the school's decision was based on the concern that $\mathrm{CC}$ may pose a cross-infection risk to two other students with $\mathrm{CF}$. Although the concern in this case was erroneous - only active (not carrier status of) CF possess crossinfection risk - consideration of factors that present a risk to public health are generally regarded as a "legitimate educational interest," and may thus justify the disclosure of student medical information.

Comparable public health considerations may exist for children with genetic proclivities for behavioral and psychiatric disorders. The growing number of diagnoses of children and adolescents with mental health issues has long been seen as an epidemic, and as mentioned earlier, there is an increasing recognition of the personal and societal costs associated with psychiatric disorders. In addition, although the vast majority of persons with psychiatric disorders do not engage in violence against others, studies suggest that small subgroups of 
persons with severe mental disorders are at increased risk of violent behavior, especially towards themselves (i.e., suicide) ${ }^{76}$ Efforts to reduce the risk for, and subsequent prevalence of, psychiatric conditions by the utilization of, among other things, student genetic profile, could thus befit public health interests. Specifically, it could be argued that if it were possible to identify factors that in the presence of certain genetic variants significantly increase or reduce the risk for developing such conditions or the likelihood of presenting antisocial outcomes (e.g., aggression), disclosure of student genetic profiles would be justified.

Support for such an argument can be found in research on genes-environment interaction. Since Caspi et al.'s seminal findings in 2002 about the interaction between child maltreatment, antisocial behavior, and the presence of an allele associated with reduced activity of the MAOA gene, ${ }^{77}$ other researchers have found an impact of early childhood environmental stressors (e.g., abuse, maternal insensitivity, parenting style) on genetic vulnerability to psychiatric disorders, including depression, ${ }^{78}$ and other children's externalizing behavior such as ADHD, impulsivity, and sensation seeking. ${ }^{79}$ Emerging findings further indicate that broader societal settings, such as poor conditions in schools and neighborhoods, may also constitute adverse childhood environments and interact with individual's genetic sensitivity to affect the risk of psychopathological outcomes. ${ }^{80}$ Furthermore, as a growing number of studies have illustrated, such gene-environment interactions are not unidirectional. That is, individuals with genetic sensitivity to the environment are as likely to benefit disproportionately from supportive environments as to be disadvantaged by adverse ones. ${ }^{81}$

Naturally, not all studies have supported these findings (see, e.g., ${ }^{82}$ ), and as discussed earlier, there is still much to be learned about the interplay between genes, environments and psychiatric disorders (e.g., which genes are relevant, what role epigenetic play, and what is the exact nature of gene-environments interaction). However, Caspi et al.'s findings have inspired ongoing research on these questions, and there is hope that such research will lead to even more conclusive findings (whether or not it is the MAOA variant or other gene candidates). Drawing on the essence of these studies to the education context, these findings suggest that disclosure of students behavioral and psychiatric genetic profiles could be justified in 3 circumstances: 1) if evidence exists about a student experiencing environmental stressors that amount to childhood adversity, a positive result of behavioral and psychiatric genetic sensitivity would allow for tailored interventions that reduce, and even reverse, the risk for developing a psychiatric condition; 2) if evidence exists about a student experiencing supportive environments, a positive result of behavioral and psychiatric genetic sensitivity would provide assurance that the interests of the individual and society in promoting mental health are properly addressed; and 3) if evidence exists about a student experiencing either environmental stressors or supportive environments, a negative result of behavioral and psychiatric genetic sensitivity would suggest that this student is not at an increased risk or is at the same risk as the general population for developing psychiatric conditions.

In practice, the circumstances that raise most urgency for reducing the prevalence and impact of psychiatric conditions, and which are thus most likely to be viewed as justifying disclosure of students behavioral and genetic profiles are those stipulated in (1), that is: the 
presence of environmental stressor and positive results of behavioral and psychiatric genetic sensitivity. As some proponents of a genomically sensitive education system postulate, even if teachers' knowledge of students' behavioral genetic profile will not have much direct impact in the classroom, it will have significant implications in terms of early diagnosis and preventative interventions that impact students' behavioral issues. ${ }^{83}$ Although the goal of prevention is clearly important, this prospect raises several sociocultural difficulties that should be considered.

Specifically, a major concern in the disclosure of student behavioral and genetic profiles is the risk of biases in determining childhood adversity and in addressing students' needs. As suggested, the most plausible circumstances to trigger the disclosure of student genetic profiles would require a determination of childhood adversity. However, distinguishing between adverse and advantageous childhood environments is not always easy. Although extreme parental behaviors such as sexual abuse or harsh physical punishment would qualify as child abuse or maltreatment, it is also the case that a universally accepted definition of child abuse and neglect does not exist, ${ }^{84}$ and that racial and ethnic groups and communities differ in their childrearing practices and in their limits of acceptable behavior. ${ }^{85}$ This may be critical in a genomically informed education system as teachers-who are overwhelmingly white-may misunderstand behaviors of non-Caucasian families ${ }^{86}$ and disproportionality make determinations of childhood adversity with regard to students of diverse cultural backgrounds.

Concurrently, distinguishing among students on the basis of their genetic makeup when adverse environments are present may come at a high cost for students who experience childhood stressors but do not have high-risk genetic variance (e.g., students with alleles associated with increased activity of the MAOA gene (scenario 3 above)), and those who attend disadvantaged school environments—overwhelmingly racial and ethnic minorities ${ }^{87}$ - and have high-risk genetic variance (scenario 1 above). Whereas the former may be (erroneously) presumed to have less need for support ${ }^{88}$ and less likely to pose burden on society, the latter would likely be missed, given the challenges involved in monitoring and improving poor educational settings.

This discussion highlights the caution required in calls to utilize student behavioral and psychiatric genetic make up as preventative measures in schools, and ties to a broader issue regarding the usefulness of genomic data in transforming social goals-such as educational attainment—at a population level. As has been discussed in the context of genomics and public health, socio-economic, structural and environmental factors rather than biological ones are the primary reason for health differences between and within groups, and the shift to a molecular-based medicine does not remedy these issues. ${ }^{89}$ The calls for a genomically informed education system raise similar concerns. That is: children's predispositions to behavioral and psychiatric conditions, as are their educational outcomes, are largely impacted by structural and environmental impediments such as familial and neighborhood poverty, high stress, and poor nutrition. ${ }^{90}$ And while perceptions of behavioral genomic data as "hard science" may contribute to their appeal as relevant information, ${ }^{91}$ a focus on such data may obscure the urgent need to address the underlying structural and environmental factors that increase the risk for behavioral and psychiatric conditions among all children 
and that negatively impact students' achievements. Thus, before behavioral and psychiatric genetic data are incorporated in student education records and disclosed to promote educational and public health interests, measures are needed to ensure that a genomically informed education system is applied with cultural sensitivity and, importantly, that it offers the necessary supports to all students—regardless of their genes-environment interaction profiles.

\section{The Who Question}

A second issue to consider is whose genomic privacy is protected, and by whom, within the educational system - a question that taps into the broader discussion about whether or not there is a need for heightened privacy protection of genetic data. In clinical settings, the debate has centered on the need for balancing between the possible misuse of genetic data and the concern that "genetic exceptionalism" (e.g., not incorporating genetic data in patients' e-medical records) would compromise patients' care. The presumed lack of relevance of genomic data in non-clinical settings, in contrast, has given more weight to concerns of genetic-based discrimination and to greater support for increased privacy protections. The Genetic Information Non-discrimination Act of 2008 (GINA) was indeed adopted for this reason, prohibiting employers and health insurers from using genetic data in their respective decisions.

The education context, however, presents a unique challenge. Although a genomically informed education system is intuitively aimed to provide some form of medically-based interventions, schools are not considered to be entities that provide clinical services. And unlike medical records that are subjected to the privacy rule under the Health Insurance Portability and Accountability Act of 1996 (HIPAA), student education records, including medical information that is incorporated in them, are regulated under the FERPA, which, as discussed above, allows for disclosure when a legitimate educational goal exists. The scope and limits of student genomic privacy are thus not as clearly delineated as they are for clinical settings.

A further complicating factor is that it is unclear whether the general legislative framework for protecting genomic privacy applies to student educational records. GINA is limited to employment and health insurance settings and it does not provide protection in other contexts, such as education, in which genetic data may be used or misused. The protection of students' genomic privacy under relevant disability laws is equally limited. The Americans with Disabilities Act, which aims to protect symptomatic individuals and those who are perceived as having a physical or mental impairment from discrimination, does not include a provision on genetic data or protection for asymptomatic individuals with genetic conditions. ${ }^{92}$ Although federal authorities have interpreted this Act to encompass employers' discrimination of employees on the basis of genetic test results, this interpretation is not legally binding. ${ }^{93}$ It is also unclear whether this interpretation wouldor should - apply to educational settings. After all, disability laws (including the Americans with Disabilities Act, the Rehabilitation Act and the Individuals with Disabilities Education Act) are designed to provide individually tailored educational services for children with disabilities. Insofar as students' behavioral and psychiatric genetic data could inform the 
provision of such tailored services and interventions, they could be viewed as fulfilling the goals of disability laws. Indeed, some scholars have even argued that a genomically informed education system may promote an up-to-date concept of equality, by tailoring interventions to individual genetic differences. ${ }^{94}$

Nonetheless, there are two reasons why consideration of students' genomic privacy is needed. First, the nature of genetic data as heritable conditions that are passed from parents to their offspring necessarily raises the risk that a student's genetic profile may reveal sensitive information not only about the child, but also about relatives, such as siblings and parents. ${ }^{95}$ The potential loss of genetic privacy may thus extend beyond the student to other relatives, regardless of whether a "legitimate educational interest" exists. Second, and related, is that the absence of clear guidelines for disclosure of student genetic profiles raises the risk that families of students from poor neighborhoods or low socio-economic stratums will be more excessively surveilled for their genomic makeup. Although such heighted surveillance may be based on the presumption that poorer families experience higher rates of environmental stressors (and are thus at higher risk for developing psychiatric conditions), it may also reinforce the marginalization of those who are already disenfranchised.

Consider, e.g., Caspi et al.'s findings of an interaction between stressful life events and the short allele of the serotonin transporter gene (5-HTT), to produce increased rates of depression. ${ }^{96}$ (Note: it is not the specific presence of the 5-HTT gene that is of critical importance for this discussion, but the notion that there are genes, some of which are currently being investigated, ${ }^{97}$ that interact with childhood adversity or "stressful life events" to produce depression.) Specifically, given that "stressful life events" could encompass a broad list of items, including employment, financial, housing, health, poor schooling, and relationship stressors (e.g., parents' divorce), a highly intrusive system for continuous reporting of such experiences to school officials will be necessary for implementing genomically informed interventions. Furthermore, almost any student—who may exhibit one of numerous possible combinations of stressors - could be viewed as being "at risk." Disclosure of students' genetic data on this basis would thus be too excessive, and, in practice, eschew notions of student (and families') genomic privacy.

Conversely, a high threshold for "stressful life events" would likely result in the singling out of students from poor neighborhoods and families where such stresses are prevalent. ${ }^{98}$ Worse, the intergenerational transmission of poverty, and, as emerging studies in epigenetics suggest, of parental imprinted genes-i.e., the effects of environmental exposures such as poor diet, anxiety, and stress on gene expression, including increased risk of behavioral and psychiatric disorders ${ }^{99}$ - may call for increased surveillance of not only currently poor students but also of those with a family history of poverty. Genomic data of (current and past) socio-economically deprived students, who are predominantly from racial and ethnic minorities, will thus be more easily disclosed than those of wealthy and Caucasian students, and reinforce a wrong perception of low socio-economic and racial/ethnic minority groups as genetically inferior populations. Moreover, as the US culture is highly individualistic, it would likely also result in increased perceptions of poor parents as responsible for their children's experience of such stressors and, thus, poor behavioral outcomes, while, once again, structural impediments are ignored. ${ }^{100}$ 
This concern is further exacerbated because it is unclear who within the educational system is, or should be, entrusted with student genetic data. ${ }^{101}$ Although existing education law and regulations permit school officials to access student education records, the term "school officials" is undefined. It may thus potentially encompass a significantly large number of people-from teachers to school administrators to other parties (as occurred in the Chadam case) — who normally wouldn't have access to such data. Thus, even if a legitimate educational goal exists and can justify access to a student's genetic profile, despite the loss of privacy, it is troubling that the scope, meaning, and implementation of such decisions may be left in the hands of individual teachers.

\section{The How Question}

The previous questions - when to disclose a student's genetic profile, whose genomic privacy is protected, and by whom-have largely focused on the challenges arising from the lack of clear boundaries for the implementation of a genomically informed education system. The question of how would student genomic data affect related education decisions calls for consideration of broader issues surrounding behavioral and psychiatric genetics, specifically: the persistent association between psychiatric disorders and stigma, perception of dangerousness, and desire for social distancing, which is likely to be interwoven into education-related decisions.

Although these have been extensively discussed with regard to psychiatric disorders in general, and when the disorder is attributed to genetic causes, in particular, ${ }^{102}$ the education context is especially worrisome. Studies indicate that educators tend to endorse the promises of science and are eager to incorporate them into the classroom. ${ }^{103}$ As the 2005 UK study of primary school teachers found, teachers expressed interest in adjusting their instructing and tracking methods to students' behavioral genetic makeup and hope for genetically-sensitive solutions for the field of education. ${ }^{104}$ However, studies also show that educators' training in genetics and genomics is limited 105 -interestingly, also when they are explicitly informed about neuropsychiatric genetic syndromes of their students ${ }^{106}$; that school curriculums about gene-environment interactions for K-12 science education are particularly poor ${ }^{107}$; and that genetic determinism with regard to health status is prevalent in the general public, which presumably includes educators. ${ }^{108}$ Indeed, although many primary school teachers in the 2005 UK study believed that environmental factors had influence on children's psychiatric conditions, it is of note that over $60 \%$ of respondents believed that such conditions are mostly caused by genes, and $\sim 9 \%$ of respondents believed that such conditions are "all genes". ${ }^{109}$ Educators and administrators who become aware of a child's genetic proclivity for a psychiatric disorder may thus assume that the child will necessarily develop the condition, irrespective of the presence of symptoms. In turn, this may lead to erroneous labeling of the child as "mentally disabled," to lower educational expectations from the child, ${ }^{110}$ and to misguided educational placement decisions. In the context of behavioral and psychiatric genetics, such placement decisions may have long-term implications. They may result in a student being transferred to special education settings-a resolution that is difficult to reverse ${ }^{111}$ and which often provide inferior curriculum and social opportunities compared to those in mainstream classrooms. 
In theory, such consequences could be substantially mitigated were teachers' psychiatric classification of students and subsequent educational placement decisions required the confirmation of a physician. However, pediatricians and other healthcare providers may not be able to provide such assistance. Studies found that although primary care providers believe that they have a role in the diagnosis, treatment and management of psychiatric conditions in children, they often lack confidence in making a diagnosis and treatment decisions (also for some of the most prevalent conditions diagnosed such as ADHD) and have difficulty allocating the time necessary for in-depth evaluation of a child. ${ }^{112}$ In addition, studies consistently show that many clinicians, including pediatricians and psychiatrists, lack requisite knowledge of genetics, especially psychiatric genetics, ${ }^{113}$ and, moreover, that they tend to demonstrate less empathy for potential patients whose psychiatric conditions are attributed to genetics (compared with patients for whom they have psychosocial information). ${ }^{114}$ Thus, notwithstanding the potential educational benefit of a genomically informed education system, caution is needed before behavioral genetic data are incorporated in student education records.

\section{Conclusions}

Although the rise of genomic data and knowledge may offer important benefits for adult and pediatric patients with behavioral and psychiatric conditions, their unregulated use in nonclinical settings - at present time and also in the future, as such data continues to emergemay lead to unintended consequences that are detrimental for individuals, families and communities. A genomically informed education system is one such glaring example. As scholars and researchers call for increased "geneticization" of children's behaviors in educational settings, there is an urgent need for inquiring how such initiatives are balanced against the necessity of investing in structural and environmental factors that increase the risk of all children for developing behavioral and psychiatric conditions and that negatively impact their educational outcomes. There is a further need for considering how such initiatives will impact those who are most marginalized, developing up-to-date programs to increase genomic literacy among educational stakeholders, including pediatricians and child psychiatrists, and drafting clear national regulations of when and how access to and use of student behavioral genetic profiles are permitted, as well as who is entrusted with this genomic responsibility. Without such initial steps, the risks for students (and families) with a genetic predisposition to behavioral and psychiatric conditions will outweigh the benefits.

\section{Acknowledgments}

This work was supported by NIH grants K01 HG008653 and P50 HG007257. I thank Paul Appelbaum, MD, for providing insight during the course of this research.

This work was supported by grant funding from the National Institutes of Health: NHGRI K01 HG008653 and P50 HG007257.

\section{References}

1. Grigorenko EL. How Can Genomics Inform Education? Mind, Brain and Education. 2007; 1(1):20 27.Reilly C, Senior J, Murtagh LA. A Comparative Study of Educational Provision for Children 
with Neurogenetic Syndromes: Parent and Teacher Survey. Journal of Intellectual Disability Ressearch. 2015; 59(12):1094-1107.

2. Grigorenko, supra note 1, at 22, 23.

3. Wold, SJ. School Health Services: History and Trends. In: Schwab, NC., Gelfman, MHB., editors. Legal Issues in School Health Services: A Resource for School Administrators, Schools Attorneys, School Nurses. NY: Authors Choice Press; 2005. p. 7-54.at 7-8

4. Id., at 8

5. Culp-Ressler, T. Three students got kicked out of an Arkansas public school because they might be HIV-positive. Think Progress. 2016. https://thinkprogress.org/three-students-got-kicked-out-of-anarkansas-public-school-because-they-might-be-hiv-positive-502f27f8bff5/ (last accessed Sep. 25, 2017)AIDS Law Project of Pennsylvania. Milton Hershey School case: A student's fight against HIV discrimination. http://www.aidslawpa.org/2012/06/abraham-smith-and-mother-smith-v-miltonhershey-school/2012 (last accessed Sep. 25, 2017)

6. Ryan J, Virani A, Austin JC. Ethical Issues Associated with Genetic Counseling in the Context of Adolescent Psychiatry. Applied and Translational Genomic. 2015; 5:23-29. at 24.

7. Dunn EC, et al. Genetic Determinants of Depression: Recent Findings and Future Directions. Harvard Review of Psychiatry. 2015; 23(1):1-18. at 12-13. [PubMed: 25563565]

8. American Academy of Pediatrics. Ethical and policy issues in genetic testing and screening of children. Pediatrics. 2013; 131(3):620-622. at 620. [PubMed: 23428972]

9. Knoppers BM. Whole-genome Sequencing in Newborn Screening Programs. Science Translational Medicine. 2014; 6(229):229cm222. at 1.

10. Moeschler JB. Medical Genetics Diagnostic Evaluation of the Child with Global Developmental Delay or Intellectual Disability. Current Opinion in Neurology. 2008; 21(2):117-122. at 118. [PubMed: 18317267] Duncan RE. An International Survey of Predictive Genetic Testing in Children for Adult Onset Conditions. Genetics in Medicine. 2005; 7(6):390-396. at 392. [PubMed: 16024970]

11. Connolly JJ, Hakonarson H. The Impact of Genomics on Pediatric Research and Medicine. Pediatrics. 2012; 129(6):1150-1160. [PubMed: 22566424] Levenseller BL, et al. Stakeholders' Opinions on the Implementation of Pediatric Whole Exome Sequencing: Implications for Informed Consent. Journal of Genetic Counseling. 2014; 23(4):552-565. [PubMed: 23846343] Henderson GE. Characterizing Biobank Organizations in the U.S.: Results from a National Survey. Genome Medicine. 2013; 5(1):1-12. at 9. [PubMed: 23311897]

12. For a comprehensive discussion on the ethical, legal and social challenges arising from the participation of chidlren, especially adolescents in genomic research and the return of genomic results to them see,Sabatello M, Appelbaum PS. Raising Genomic Citizens: Adolescents and the Return of Secondary Genomic Findings. Journal of Law, Medicine and Ethics. 2016; 44(2):292308.

13. Robertson JA. Extending Preimplantation Genetic Diagnosis: The Ethical Debate. Ethical Issues in New Uses of Preimplantation Genetic Diagnosis. Human Reproducation. 2003; 18(3):465-471.

14. Franasiak, J., Scott, RT. A brief history of preimplantation genetic diagnosis and preimplantation genetic screening. 2008. http://www.ivf-worldwide.com/cogen/oep/pgd-pgs/history-of-pgd-andpgs.html (last accessed Sep. 25, 2017)

15. Craven L. Research into Policy: A Brief History of Mitochondrial Donation. Stem Cells. 2016; 34(2):265-267. [PubMed: 26418557]

16. National Academies of Sciences Engineering and Medicine. Mitochondrial Replacement Techniques: Ethical, Social, and Policy Considerations. Washington, DC: The National Academies Press; 2016. at 106-108

17. National Academies of Sciences Engineering and Medicine. Human Genome Editing: Science, Ethics, and Governance. Washington, DC: The National Academies Press; 2017. at 136-7

18. Wilde A. Implications of the Use of Genetic Tests in Psychiatry, with a Focus on Major Depressive Disorder: A Review. Depression and Anxiety. 2013; 30(3):267-275. at 269-270. [PubMed: 22987566]

19. 23andMe. Compare our DNA tests. https://www.23andme.com/compare-dna-tests/ (last accessed Sep 25 2017) 
20. FDA. FDA allows marketing of first direct-to-consumer tests that provide genetic risk information for certain conditions. Apr 6, 2017. https://www.fda.gov/NewsEvents/Newsroom/ PressAnnouncements/ucm551185.htm (last accessed Sep. 25, 2017)

21. Tercyak KP. Parents' Attitudes Toward Pediatric Genetic Testing for Common Disease Risk. Pediatrics. 2011; 127(5):e1288-1295. at e1292-3. [PubMed: 21502235]

22. Lawrence RE, Appelbaum PS. Genetic Testing in Psychiatry: A Review of Attitudes and Beliefs. Psychiatry. 2011; 74(4):315-331. at 323-4. [PubMed: 22168293] Erickson JA. Genetic Testing of Children for Predisposition to Mood Disorders: Anticipating the Clinical Issues. Journal of Genetic Counseling. 2014; 23(4):566-577. at 570-2, 574. [PubMed: 24651919]

23. Duncan LE, Keller MC. A Critical Review of the First 10 years of Candidate Gene-by Environment Interaction Research in Psychiatry. American Journal of Psychiatry. 2011; 168:10419. at 1047-8. [PubMed: 21890791] Duncan LE, Pollastri AR, Smoller JW. Mind the Gap: Why Many Geneticists and Psychological Scientists Have Discrepant Views about Gene-Environment Interaction (GxE) Research. American Psychologist. 2014; 69:249-68. at 254-5, 261. [PubMed: 24750075]

24. Denno DW. Courts' Increasing Consideration of Behavioral Genetics Evidence in Criminal Cases: Results of a Longtitudinal Study. Michigan State Law Review. 2011; 2011:967-1047.Denno, DW. Behavioral Genetics Evidence in Criminal Cases: 1994-2007. In: Farahany, NA., editor. The Impact of Behavioral Sciences on Criminal Law. New York: Oxford Press; 2009. at 317-354, 465-398Forzano F, et al. Italian Appeal Court: A Genetic Predisposition to Commit Murder? European Journal of Human Genetics. 2010; 18(5):519-521. [PubMed: 20216573] McSwiggan S, Elger B, Appelbaum PS. The Forensic Use of Behavioral Genetics in Criminal Proceedings: Case of the MAOA-L Genotype. International Journal of Law and Psychiatry. 2017; 50:17-23. [PubMed: 27823806]

25. Plonit v. The Attorney General. Court case number 3-14. Feb.. 2015. District Court Tel Aviv-Jaffa Hebrew, available at http://www.psakdin.co.il/Court/598126\#.VZqVPOseXdm (last accessed Sep. 27, 2017)Sabatello M, Appelbaum PS. Behavioral Genetics in Criminal and Civil Courts. Harvard Review of Psychiatry. 2017; 25:289-301. [PubMed: 29117024]

26. Adacsi v Amin, Docket 1201-0330-AC, 2013 ABCA 315. Ct. App. Alberta, Canada; 2013

27. Rothstein MA, Rothstein L. How Genetics Might Affect Real Property Rights: Currents in Contemporary Bioethics. Journal of Law, Medicine and Ethics. 2016; 44(1):216-221.

28. Ptak C, Petronis A. Epigenetic Approaches to Psychiatric Disorders. Dialogues in Clinical Neuroscience. 2010; 12(1):25-35. [PubMed: 20373664]

29. GlobeNewswire. GWG Life becomes first insurtech firm to collect epigenetic samples to analyze biomarkers of life insurance policy owners. https://globenewswire.com/news-release/ 2017/03/02/930557/0/en/GWG-Life-Becomes-First-Insurtech-Firm-to-Collect-EpigeneticSamples-to-Analyze-Biomarkers-of-Life-Insurance-Policy-Owners.html (last accessed Sep. 25, 2017)

30. Collins, FS. Francis Collins says medicine in the future will be tailored to your genes; the director of the national institutes of health says cheaper DNA sequencing will make personalized care routine. Wall Street Journal. 2014. Jul 07. https://www.wsj.com/articles/francis-collins-saysmedicine-in-the-future-will-be-tailored-to-your-genes-1404763139 (last accessed Feb. 11, 2018) (last accessed Feb. 12, 2018)

31. Collins FS, et al. A vision for the future of genomics research. Nature. 2003; 422(6934):835-847. at 841. [PubMed: 12695777]

32. Gason AA, et al. It's "Back to School" for Genetic Screening. Europen Journal of Human Genetics. 2006; 14(4):384-389. at 385-6.

33. Id.;Ross LF. Heterozygote Carrier Testing in High Schools Abroad: What Are the Lessons for the U.S.? Journal of Law, Medicine and Ethics. 2006; 34(4):753-764. at 753-5, 757-8.

34. Gason et al. supra note 32, at 385 .

35. Delatycki MB, et al. Implementation of IronXS: A study of the Acceptability and Feasibility of Genetic Screening for Hereditary Hemochromatosis in High Schools. Clinical Genetics. 2010; 77(3):241-248. at 241. [PubMed: 19930418] 
36. Delatycki MB, et al. IronXS: High-School Screening for Hereditary Haemochromatosis is Acceptable and Feasible. European Journal of Human Genetics. 2012; 20(5):505-509. at 508. [PubMed: 22234159]

37. Salari K, et al. Evidence that Personal Genome Testing Enhances Student Learning in a Course on Genomics and Personalized Medicine. PLoS One. 2013; 8(7):e68853. [PubMed: 23935898] Sanderson SC, et al. How Do Students React to Analyzing their Own Genomes in a Wholegenome Sequencing Course?: Outcomes of a Longitudinal Cohort Study. Genetics in Medicine. 2015; 17(11):866-874. [PubMed: 25634025]

38. Park, M. NCAA genetic screening rule sparks discrimination concerns. Aug 4, 2010. http:// www.cnn.com/2010/HEALTH/08/04/ncaa.sickle.genetic.screening/ (last accessed Sep 25, 2017)

39. ACSM and NCAA Joint Statement on Sickle Cell Trait and Exercise. Aug 23, 2013. http:// www.ncaa.org/health-and-safety/medical-conditions/acsm-and-ncaa-joint-statement-sickle-celltrait-and-exercise-0 (last accessed Sep. 25, 2017)

40. Lewin, T. College bound, DNA swab in hand. New York Times. May 18, 2010. http:// www.nytimes.com/2010/05/19/education/19dna.html (last accessed Sep. 25, 2017)Ferris, J. Exposing the student body: Stanford joins UC Berkeley in controversial genetic testing of students. Jul 6, 2010. https://www.scientificamerican.com/article/exposing-the-student-body/ (last accessed Sep 25, 2017)Callier SL. Swabbing Students: Should Universities be Allowed to Facilitate Educational DNA Testing? The American Journal of Bioethics: AJOB. 2012; 12(4):32-40. at 32.

41. Dick DM, et al. Spit for Science: Launching a Longitudinal Study of Genetic and Environmental Influences on Substance Use and Emotional Health at a Large US University. Frontiers in Genetics. 2014; 5:1-12. Article 47. [PubMed: 24567736]

42. Dick DM, Hancock LC. Integrating Basic Research with Prevention/Intervention to Reduce Risky Substance Use among College Students. Frontiers in Psychology. 2015; 6:1-6. Article 544. at 4-5. [PubMed: 25688217]

43. Snyder, TD., Dillow, SA., Digest of Education Statistics. National Center for Education Statistics, Institute of Educatino Sciences. US Department of Education; Washington DC: 2012. 2013, http:// nces.ed.gov/pubs2014/2014015.pdf (last accessed Sep. 25, 2017, at 198)

44. Wagner MM. Outcomes for Youths with Serious Emotional Disturbance in Secondary School and Early Adulthood. Critical Issues in Children \& Youth. 1995; 5(2):90-112. at 100.

45. Burrell, S., Warboys, L. Special Education and the Juvenile Justice System. Juvenile Justice Bulletin. Jul, 2000. at 1, http://youthjusticenc.org/download/juvenile-justice/juvenile-and-criminalrepresentation/Special\%20Education\%20and\%20the\%20Juvenile\%20Justice\%20System.pdf (last accessed Sep. 27, 2017)

46. See Dunn et al. supra note 7; Ptak and Petronis, supra note 28.

47. Grigorenko, supra note 1, at 22, 23Plomin R, Kovas Y, Haworth CMA. Generalist Genes: Genetic Links between Brain, Mind, and Education. Mind Brain and Education. 2007; 1(1):11-19. at 17. Haworth, CMA., Plomin, R. Genetics and Education: Toward a Genetically Sensitive Classroom. In: Harris, KR., et al., editors. APA Educational Psychology Handbook. The American Psychological Association; 2012. p. 529-559.at 551-2Plomin R, Walker SO. Genetics and Educational Psychology. British Journal of Educational Psychology. 2003; 73(Pt 1):3-14. at 9-10. [PubMed: 12639274]

48. Grigorenko, supra note 1, at 23Rothstein M. Legal Conceptions of Equality in the Genomic Age. Law and Inequality. 2007; 25:429-471. at 459-60. [PubMed: 21666871]

49. Lewis GJ, Asbury K, Plomin R. Externalizing Problems in Childhood and Adolescence Predict Subsequent Educational Achievement but for Different Genetic and Environmental Reasons. Journal of Child Psychology and Psychiatry. 2017; 58(3):292-304. [PubMed: 27861883] Rueda MR, et al. Training, Maturation, and Genetic Influences on the Development of Executive Attention. Proceedings of the National Academy of Sciences of the United States of America. 2005; 102(41):14931-14936. [PubMed: 16192352] Hodapp RM, Fidler DJ. Special Education and Genetics: Connections for the 21st Century. The Journal of Specical Educcation. 1999; 33(3):130 137. at 134-5.

50. Reilly C. Behavioural Phenotypes and Special Educational Needs: Is Aetiology Important in the Classroom? Journal of Intellectual Disability Research. 2012; 56(10):929-946. at 934. [PubMed: 22471356] 
51. Petrill SA, Justice LM. Bridging the Gap Between Genomics and Education. Mind Brain and Education. 2007; 1(4):153-161. at 157.

52. Lawrence and Appelbaum, supra note 22, 323-4; Erickson, et al. supra note 22, at 572.

53. Walker SO, Plomin R. The Nature-Nurture Question: Teachers' Perceptions of How Genes and the Environment Influence Educationally Relevant Behavior. Educational Psychology. 2005; 25:509_ 516. at 512-13.

54. Wilde A, et al. Community Attitudes to Genetic Susceptibility-Based Mental Health Interventions for Healthy People in a Large National Sample. Jouranl of Affective Disorders. 2011; 134(1-3): 280-287. at 283. May ME, Brandt RC, Bohannan JK. Moderating Effects of Autism on Parent Views of Genetic Screening for Aggression. Intellectual and Developmental Disabilities. 2012; 50(5):415-425. at 420. [PubMed: 23025643]

55. Gason AA, et al. Genetic Susceptibility Screening in Schools: Attitudes of the School Community towards Hereditary Haemochromatosis. Clinical Genetics. 2005; 67(2):166-174. at 169, 170. [PubMed: 15679829] Delatycki et al. supra note 35, at 244.

56. Walker and Plomin, supra note 53, at 512-13

57. Gason et al. supra note 55, at 169.

58. Athanasiadis G, et al. Spitting for Science: Danish High School Students Commit to a Large-Scale Self-Reported Genetic Study. PLoS One. 2016; 11(8):e0161822. at 2, 7. [PubMed: 27571202]

59. Grigorenko, supra note 1, at 21.

60. Haworth and Plomin, supra note 47, at 551-2.

61. Individuals with Disability Education Act (IDEA), 20 U.S.C. $\$ \S 1414(a)(1)$, (b)(2)-(3); Timothy v. PASO Robles Unified School District, No. 14-55800, D.C. No. 2:12-cv-06385-JGB-JEM (U.S. Court of Appeals, Ninth Circuit; 2016), at 15-6, 27-32.

62. Chabris CF, et al. Why It Is Hard to Find Genes Associated with Social Science Traits: Theoretical and Empirical Considerations. American Journal of Public Health. 2013; 103(Suppl 1):S152-166. at S153. [PubMed: 23927501]

63. Sullivan PF, Daly MJ, O’Donovan M. Genetic Architectures of Psychiatric Disorders: The Emerging Picture and Its Implications. Nature Reviews Genetics. 2012; 13(8):537-551.Sullivan, PF., et al. Psychiatric Genomics: An Update and an Agenda. BioRxiv. 2017. at 2-3, https:// www.biorxiv.org/content/early/2017/03/10/115600 (last accessed Sep 25, 2017)

64. Hart SJ, et al. Communication of Psychiatric Risk in 22q11.2 Deletion Syndrome: A Pilot Project. Journal of Genetic Counseling. 2016; 25(1):6-17. at 6. [PubMed: 26578232]

65. Young AS, et al. Discordance in Diagnoses and Treatment of Psychiatric Disorders in Children and Adolescents with 22q11.2 Deletion Syndrome. Asian Journal of Psychiatry. 2011; 4(2):119-124. at 119,121 . [PubMed: 21743818]

66. See, e.g.Nestler EJ, et al. Epigenetic Basis of Mental Illness. Neuroscientist. 2016; 22(5):447-463. [PubMed: 26450593] Uher R. Gene-Environment Interactions in Severe Mental Illness. Frontiers in Psychiatry. 2014; 5:1-9. Article 48. [PubMed: 24478729]

67. Turkheimer, E. Mobiles: A Gloomy View of Research into Complex Human Traits. In: Parens, E.Chapman, AR., Press, N., editors. Wrestling with Behavioral Genetics. Baltimore: John Hopkins University Press; 2006. p. 100-108.at 103-4

68. Id., at 105.

69. Appelbaum PS. Who's Afraid of Psychiatric Genomics? The American Journal of Bioethics: AJOB. 2017; 17(4):15-17. at 16.

70. Sullivan, Daly, and O'Donovan, supra note 63, at 547-8.

71. Ripke S, et al. on behalf of the Schizophrenia Working Group of the Psychiatric Genomics Consortium. Biological Insights from 108 Schizophrenia-Associated Genetic Loci. Nature. 2014; 511(7510):421-427. [PubMed: 25056061]

72. Sullivan et al. Psychiatric genomics, supra note 63 , at 8 .

73. Reilly, supra note 50, at 930.

74. The Family Educational Rights and Privacy Act (FERPA), 20 U.S.C. § 1232g; 34 CFR Part 99.

75. Chadam v. Palo Alto Unified School District, WL 325323 (N.D. Cal. 2014). 
76. McGinty EE, et al. Using Research Evidence to Reframe the Policy Debate around Mental Illness and Guns: Process and Recommendations. American Jouranl of Public Health. 2014; 104(11):e2226. at e22.

77. Caspi A, et al. Role of Genotype in the Cycle of Violence in Maltreated Children. Science. 2002; 297(5582):851, 854. at 853. [PubMed: 12161658]

78. Caspi A, et al. Influence of Life Stress on Depression: Moderation by a Polymorphism in the 5HTT Gene. Science. 2003; 301(5631):386-389. at 388-9. [PubMed: 12869766] Aguilera M, et al. Early Adversity and 5-HTT/BDNF Genes: New Evidence of Gene-Environment Interactions on Depressive Symptoms in a General Population. Psycholological Medicine. 2009; 39(9):14251432. at 1429.

79. Bakermans-Kranenburg MJ, van Ijzendoorn MH. Gene-environment Interaction of the Dopamine D4 Receptor (DRD4) and Observed Maternal Insensitivity Predicting Externalizing Behavior in Preschoolers. Developmental Psychobiology. 2006; 48(5):406-409. at 407-8. [PubMed: 16770765] Sheese BE, et al. Parenting Quality Interacts with Genetic Variation in Dopamine Receptor D4 to Influence Temperament in Early Childhood. Developement and Psychopathology. 2007; 19(4):1039-1046. at 1042-5. Bakermans-Kranenburg MJ, et al. Experimental Evidence for Differential Susceptibility: Dopamine D4 Receptor Polymorphism (DRD4 VNTR) Moderates Intervention Effects on Toddlers' Externalizing Behavior in a Randomized Controlled Trial. Developmental Psychology. 2008; 44(1):293-300. at 296-8. [PubMed: 18194028] Knafo A, Israel S, Ebstein RP. Heritability of Children's Prosocial Behavior and Differential Susceptibility to Parenting by Variation in the Dopamine Receptor D4 Gene. Development and Psychopathology. 2011; 23(1):53-67. at 63-4. [PubMed: 21262039] Nederhof E, et al. Effects of Divorce on Dutch Boys' and Girls' Externalizing Behavior in Gene x Environment Perspective: Diathesis Stress or Differential Susceptibility in the Dutch Tracking Adolescents' Individual Lives Survey study? Development and Psychopathology. 2012; 24(3):929-939. at 935-7. [PubMed: 22781863]

80. Liu H, Li Y, Guo G. Gene by Social-Environment Interaction for Youth Delinquency and Violence: Thirty-Nine Aggression-related Genes. Socical Forces. 2015; 93(3):881-903. at 896-7. Beaver KM, et al. The Interplay between Neighborhood and Individual Factors in the Explanation of Delinquency, Victimization, and Related Outcomes. Youth Violence and Juvenile Justice. 2012; 10(1):25-40. at 36.

81. Belsky L, et al. Vulnerability Genes or Plasticity Genes? Molecular Psychiatry. 2009; 14(8):746754. at 751-2. [PubMed: 19455150] Belsky J, Bakermans-Kranenburg MJ, van IJzendoorn MH. For Better and For Worse: Differential Susceptibility to Environmental Inluences. Current Directions in Psychological Science. 2007; 16(6):300-304. at 301-2.

82. Prichard Z, et al. No Evidence for Interaction between MAOA and Childhood Adversity for Antisocial Behavior. American Jouranl of Medical Genetics B Neuropsychiatric Genetics. 2008; 147b(2):228-232. at 231. Haberstick BC, et al. MAOA Genotype, Childhood Maltreatment, and Their Interaction in the Etiology of Adult Antisocial Behaviors. Biological Psychiatry. 2014; 75(1):25-30. at 29. [PubMed: 23726513] Vassos E, Collier DA, Fazel S. Systematic MetaAnalyses and Field Synopsis of Genetic Association Studies of Violence and Aggression. Molecular Psychiatry. 2014; 19(4):471-477. at 472. [PubMed: 23546171]

83. Haworth and Plomin, Genetics and education, supra note 47, at 551.

84. Korbin, JE. Child Maltreatment in Cross-cultural Perspective: Vulnerable Children and Circumstances. In: Gelles, RJ., Lancester, JB., editors. Child Abuse and Neglect: Biosocial Dimensions. New York: Aldin De Gruyter; 1987. p. 31-55.at 34

85. Ferrari AM. The Impact of Culture upon Child Rearing Practices and Definitions of Maltreatment. Child Abuse and Neglect. 2002; 26:793-813. at 809-10. [PubMed: 12363332]

86. Hosp JL, Reschly DJ. Referral Rates for Intervention or Assessment: A Meta-Analysis of Racial Differences. Journal of Special Education. 2003; 37(2):67-80. at 68.

87. Aud, S., Fox, MA., Kew, I., Ramani, A. Status and Trends in the Education of Racial and Ethnic Groups. 2010. https://nces.ed.gov/pubs2010/2010015.pdf (last accessed Sep. 25, 2017), at 23

88. Rothstein, LF. Genetic Information in Schools. In: Rothstein, M., editor. Genetic Secrets: Protecting Privacy and Confidentiality in the Genetic Era. New Haven \& London: Yale University Press; 1997. p. 317-331.at 323Wasserman D. Is There Value in Identifying Individual Genetic Predispositions to Violence? Journal of Law, Medicine, and Ethics. 2004; 32:24-33. at 28. 
89. Bayer R, Galea S. Public Health in the Precision-Medicine Era. New England Journal of Medicine. 2015; 373(6):499-501. at 500. [PubMed: 26244305]

90. Chaudry A, Wimer C. Poverty is Not Just an Indicator: The Relationship Between Income, Poverty, and Child Well-Being. Academic Pediatrics. 2016; 16(Suppl 3):S23-29. at S26-7. [PubMed: 27044698]

91. John P. When Neurogenetics Hurts: Examining the Use of Neuroscience and Genetic Evidence in Sentencing Decisions Through Implicit Bias. California Law Review. 2015; 103:1019-45. at 1027-29.

92. Rothstein MA. Currents in Contemporary Ethics: GINA, the ADA, and Genetic Discrimination in Employment. Journal of Law, Medicine and Ethics. 2008; 36(4):837-840. at 838.

93. Id.Commission USEEO. What You Should Know about EEOC Regulations, Subregulatory Guidance and other Resource Documents. https://www1.eeoc.gov//eeoc/newsroom/wysk/ regulations_guidance_resources.cfm?renderforprint=1 (last accessed Sep 26, 2017)

94. Rothstein, supra note 48, at 459, 462.

95. Rothstein, supra note 88 , at 323 .

96. Caspi et al. supra note 78 at $388-9$.

97. Dunn et al. supra note 7, at 11-14.

98. Beaver et al. supra note 80, at 28-9; Wasserman, supra note 88, at 28.

99. Boersma GJ, et al. Long-Term Impact of Early Life Events on Physiology and Behaviour. Journal of Neuroendocrinology. 2014; 26(9):587-602. [PubMed: 24690036] Bowers ME, Yehuda R. Intergenerational Transmission of Stress in Humans. Neuropsychopharmacology. 2016; 41(1): 232-244. at 233-5. [PubMed: 26279078]

100. Nelkin D, Tancredi L. Classify and Control: Genetic Information in the Schools. Americna Jounal of Law and Medince. 1991; 17:51-73. at 70. Wasserman D. Ethical and Policy Issues in Genetic Prediction of Violence: Implications for Clinicians. Current Genetic Medicine Reports. 2014; 2:216-222. at 218-9.

101. Rothstein, supra note 88 , at 323-4.

102. See, e.g.Phelan JC, Yang LH, Cruz-Rojas R. Effects of Attributing Serious Mental Illnesses to Genetic Causes on Orientations to Treatment. Psychiatric Services. 2006; 57(3):382-387. [PubMed: 16524997] Pescosolido BA, et al. "A Disease Like Any Other"? A Decade of Change in Public Reactions to Schizophrenia, Depression, and Alcohol Dependence. American Journal of Psychiatry. 2010; 167(11):1321-1330. [PubMed: 20843872] Parcesepe AM, Cabassa LJ. Public Stigma of Mental Illness in the United States: A Systematic Literature Review. Administration and Policy in Mental Health. 2013; 40(5):384-399. [PubMed: 22833051] Read J, et al. Prejudice and Schizophrenia: A Review of the 'Mental Illness Is an Illness Like Any Other' Approach. Acta Psychiatrica Scandinavica. 2006; 114(5):303-318. [PubMed: 17022790]

103. Nelkin and Tancredi, supra note 99, at 66.

104. Walker and Plomin, supra note 53, at 515.

105. Id., at 512; Grigorenko, supra note 1, at 24.

106. Reilly, Senior and Murtagh, supra note 1, 1099.

107. Dougherty MJ. Closing the Gap: Inverting the Genetics Curriculum to Ensure an Informed Public. American Jouranl of Human Genetics. 2009; 85(1):6-12. at 7. Dougherty MJ, et al. A Comprehensive Analysis of High School Genetics Standards: Are States Keeping Pace with Modern Genetics? CBE Life Sciences Education. 2011; 10(3):318-327. at 324-6. [PubMed: 21885828]

108. Scurich N, Appelbaum PS. The Blunt-Edged Sword: Genetic Explanations of Misbehavior Neither Mitigate Nor Aggravate Punishment. Journal of Law and the Biosciences. 2015; 3(1): 140-157. at 155. [PubMed: 27239327]

109. Walker and Plomin, supra note 53, at 512.

110. Rothstein, supre note 88, at 322; Nelkin and Tancredi, supra note 100, at 69-70.

111. Hoge MR, et al. Examining Placement Considerations for Students with Emotional Disturbance Across Three Alternative Schools. Journal of Disability Policy Studies. 2014; 24(4):218-226. at 223. 
112. Power TJ, et al. Managing Attention-Deficit/Hyperactivity Disorder in Primary Care: A Systematic Analysis of Roles and Challenges. Pediatrics. 2008; 121(1):e65-72. at e66. [PubMed: 18166546] Shaw KA. Attitudes and Practices of General Practitioners in the Diagnosis and Management of Attention-Deficit/Hyperactivity Disorder. Journal of Paediatrics and Child Health. 2002; 38(5):481-486. [PubMed: 12354265]

113. Finn CT, et al. Psychiatric Genetics: A Survey of Psychiatrists' Knowledge, Opinions, and Practice Patterns. Journal of Clinical Psychiatry. 2005; 66(7):821-830. at 824-5. [PubMed: 16013896] Mikat-Stevens NA, Larson IA, Tarini BA. Primary-Care Providers' Perceived Barriers to Integration of Genetics Services: A Systematic Review of the Literature. Genetics in Medicine. 2015; 17(3):169-176. at 171-2. [PubMed: 25210938] Baars MJ, Henneman L, Ten Kate LP. Deficiency of Knowledge of Genetics and Genetic Tests among General Practitioners, Gynecologists, and Pediatricians: A Global Problem. Genetics in Medince. 2005; 7(9):605-610. at 608-9.

114. Lebowitz MS, Ahn WK. Effects of Biological Explanations for Mental Disorders on Clinicians' Epathy. Proceedings of the National Academy of Sciences of the United States of America. 2014; 111(50):17786-17790. at 17788. [PubMed: 25453068] 